\title{
Toward Determining Changes in Engineering-Related Social Capital: Resource Composition as Students Make Decisions About College
}

\author{
Matthew K. Miller \\ Dept. of Engineering and Science Education, Clemson University, Clemson, South Carolina, \\ USA \\ E-mail:mkmille@gmail.com \\ Julie P. Martin (Corresponding Author) \\ Dept. of Engineering and Science Education, Clemson University, Clemson, South Carolina, \\ USA \\ E-mail: martin1@clemson.edu
}

Marisa K. Orr

Dept. of Mechanical Engineering, Louisiana Tech University, Ruston, Louisiana, USA

E-mail: marisao@latech.edu

Received: February 21, 2014 Accepted: March 6, 2014 Published: March 16, 2014

doi:10.5296/jet.v1i2.5158 URL: http://dx.doi.org/10.5296/jet.v1i2.5158

\begin{abstract}
Applying Lin's Network Theory of Social Capital, a survey instrument developed by the research team was used to capture information regarding the size, structure, and composition of students' social networks and resources related to engineering studies and careers. Data were collected from 1,410 undergraduate engineering students at five institutions in the United States. Participants were asked to reflect back to the time when they were deciding to major in engineering, identify names of people they considered influential to their decision (forming their engineering-related social network), and identify resources that were accessed through these networks. Cluster analysis was used to group participants according to social capital characteristics including network size, strength of ties, heterophily or diversity of
\end{abstract}


relationships, and embedded resources. Two separate cluster analyses were conducted. The analysis based on social network characteristics yielded a three-cluster solution, identifying one group with larger networks consisting of both strong and weak ties, and two groups with smaller networks, one reporting more use of strong, family-based ties and the other reporting more influence from weaker, non-family ties. The analysis based on engineering-related resources grouped students into two categories: one reporting higher access to engineering-related resources and another group which reported, on average, lower access to each resource. Demographic analyses of the clusters revealed lower resource access was most often reported by Hispanic, first generation in college, and lower-income students while higher resource access was reported by more students who have an engineer parent or who knew an engineer before college.

Keywords: social capital, engineering education, cluster analysis, underrepresented groups, recruitment, persistence

\section{Introduction}

In the United States, great emphasis has been placed in recent years on increasing both the number and diversity of postsecondary students studying engineering and, ultimately, entering the engineering workforce. Educators, industry, and government-funded agencies have placed particular emphasis on recruiting and retaining demographic groups that have been historically underrepresented in engineering higher education, including women, racial/ethnic minorities (particularly Hispanics, African-Americans and Native Americans/Pacific Islanders), first generation college students and students from lower-income families. While significant resources have been devoted to increasing the diversity of the U.S. engineering "pipeline," progress in increasing representation among certain groups has been disturbingly slow (National Science Foundation, 2012). We assert that the theoretical framework of social capital is appropriate for studying student's experiences related to selecting and persisting in undergraduate engineering studies because engineering has been described as a privileged profession or "closed club" (Ohland et al., 2008) with associated "occupational inheritance" (Mannon \& Schreuders, 2007). The work described in this paper is part of a mixed-methods study with the long-term objective of developing a conceptual model for understanding how engineering undergraduates develop, access, and activate engineering-related social capital in making academic and career decisions.

Social capital theory is rooted in the field of sociology, with Bourdieu being the first to refer to the concept as such: "[s]ocial capital is the aggregate of the actual or potential resources which are linked to possession of a durable network ... or in other words, to membership in a group ... which provides each of its members with the backing of the collectively-owned capital, a 'credential' which entitles them to credit, in the various senses of the word" (Bourdieu, 1986, p. 248). An output of Bourdieu's original thoughts on social capital and the primary theoretical foundation of the present study, Lin's perspective of social capital at the level of the individual's (or "ego's") network describes social capital as an intangible set of "resources gained through relationships" (Lin, 2001, p. 23) that can be built, maintained, and 
exchanged between people, much like financial capital. While most social capital work resides in the domain of sociology, this theory has been used in economics, management, healthcare, and other settings. In fact, there are many studies that discuss the impact of social capital on education (e.g., Tonkaboni, Yousefy, \& Keshtiaray, 2014), but few do so within the context of engineering education. We are the first to develop and utilize an instrument that captures detailed information about the quantity and quality of relationships students have with individuals who are influential to their decision to pursue engineering. Through this instrument, we are also able to provide information about engineering academic and career-related resources available within students' networks at two points in time. Our "Name and Resource Generator" (NRG) instrument was inspired by two tools used in sociology - the Name Generator (Lin, 1999a), designed to determine detailed information about an individual's ("ego") social ties (network of "alters"), and the Resource Generator (Van der Gaag \& Snijders, 2005), designed to gather information about access to specific social resources. Our combination of the two types of instruments helps to not only collect data about individual network members that immediately come to a participants' mind, but also to elicit information about access to specific resources that the participant may not have immediately been able to recall during the earlier portion of the survey. (Details of the development (Martin, Gipson, \& Miller, 2011) and validation (Martin, Miller, \& Gipson, 2011) of this instrument have previously been reported; please refer to these references for additional details.)

Specifically, in this paper, we take a critical step toward achieving our long-term goal by investigating the following two research questions:

1) When grouping students based on their social capital characteristics, which aspects of their social networks and resource availability create the most distinction between each group? ("What are the clusters?")

2) What demographic differences exist among the students in each social capital cluster, and are there any that lead to important findings about underrepresented groups in engineering? ("Who is in the clusters?")

Answering these research questions will reveal critical information about students' development (or lack thereof) of social capital that can help (or hinder) their ability to successfully enter and persist in engineering fields, and ultimately enter the nation's engineering workforce. Furthermore, clusters based on social capital characteristics will be compared in order to identify significant differences related to the demographics of each group, with a particular emphasis on underrepresented groups). We will discuss these findings and their implications for engineering education. Stakeholders in higher education can use this information to better target recruitment and retention efforts by understanding what has worked for current students and where opportunities for improvement still exist.

\section{Theoretical Framework: Network Theory of Social Capital}

The literature on social capital published in the last 25 years is vast. In reviewing research relevant to the present study, several key challenges to measuring social capital are revealed: 
1) there is not a common definition of social capital, 2) there is not a common way to operationalize social capital, and 3) definitions and measures of social capital seem to be largely context-dependent. Considering these observations, we focus on applications of social capital that are both supported by prior work and are appropriate to our context in engineering education. To the extent possible, we aim to present a comprehensive view of engineering-related social capital available to and accessed by students during the time they were considering engineering as an undergraduate major. Thus, our analysis includes social network indicators as well as social capital resources. Subsequent analysis will then inform us about students' demographic aspects that may influence their engineering-related social capital during this critical time in their career development. First we will discuss uses and benefits of social capital relevant to our study from the literature, followed by a presentation of how we measure and use social capital in our analysis.

\subsection{Uses and Applications of Social Capital Relevant to a Higher Education Context}

One application of social capital relevant to our study comes from the fields of economics and management; in particular, organizational theory. Adler and Kwon's synthesis of social capital research in this area discusses the influence of social capital within the structure of an organization (e.g. a business or company), demonstrating its influence on career success, helping workers find jobs, reducing turnover rates, and facilitating the exchange of resources between business units (Adler \& Kwon, 2002). As college major selection and persistence is an earlier step in the career-seeking process, it is our position that studying social capital in the context of higher education may yield similar benefits.

Some such knowledge in the area of engineering education already exists - for example, as pointed out by Brown and colleagues, we know that social capital has been positively linked to retention, academic achievement, grade point average, and self-confidence for engineering students (Brown, Flick, \& Fiez, 2009). Much of this work was a result of considering social capital as it develops within a classroom or learning community, revealing benefits of the interactions between a student and their fellow peers, teaching assistants, and faculty members (e.g., Brown et al., 2009; Brown \& Hildreth, 2007; Brown, 2005; Dika, 2012). There is also evidence suggesting that students develop social capital through student clubs and organizations, such as engineering sororities and fraternities, and student chapters of professional engineering societies (Daily, Eugene, \& Prewitt, 2007a; Daily, Eugene, \& Prewitt, 2007b; Trenor, Simmons, \& Archer, 2010).

However, much less is known about how social capital develops and influences students before they enter the undergraduate engineering classroom. We do not know specifically how students gain access to social capital resources, what resources are more important for engineering, or how this impacts students' selection of and persistence in engineering majors. Furthermore, more knowledge is needed about students that are at risk of not having the necessary social capital to help them enter and/or successfully persist in engineering fields.

It is generally acknowledged that social capital is not permanent and thus can change over time (Blumberg, Peiro, \& Roe, 2012). Some authors have pointed to the importance of considering the temporal nature of social capital (e.g., McPherson, Smith-Lovin, \& Cook, 
2001; Nahapiet \& Ghoshal, 1998), yet this is still a theoretical gap that has been "rarely acknowledged in the literature" (Blumberg et al., 2012, p. 63). Understanding how an engineering students' social capital changes over time has the potential to be very important for understanding issues of persistence in engineering education. Our research therefore focuses on two time points: before students entered engineering programs, and as engineering undergraduates. This paper presents work that measures and classifies students according to their engineering-related social capital before they entered undergraduate engineering programs - that is, during the time they were considering engineering as a college major. Future work will explore the second time point and give us insights into students' social capital characteristics and accessed resources while they are enrolled in undergraduate engineering studies.

\subsection{Operationalizing Social Capital}

Blumberg and colleagues recently stated "[a]lthough the distinction between social networks and social capital is clear, researchers often use properties of social networks, such as density, centrality and so on, as indicators for social capital. Such structural measures neglect, however, the heterogeneity of members (providers) in terms of resource possessions" (Blumberg et al., 2012, p. 69). This recent quote highlights one of the challenges of social capital to which we alluded at the beginning of this section - identifying the most appropriate way to operationalize social capital.

Nahapiet and Ghoshal (1998) consider three facets of social capital dealing with structural details of an individual's network (e.g. how many ties, how close/distant the network is), cognitive similarities among members (e.g. shared languages/experiences developed in communities, families, and friendships), and relational attributes (e.g. trust, norms, and obligations which impact the likelihood of exchanging resources). While the context of their study (social capital impacting development of intellectual capital) differs greatly from ours, the notion of considering different dimensions of social capital has important considerations for our application of social capital. Using multiple indicators for social capital is particularly appropriate given our use of Lin's definition of social capital: "resources gained through relationships" (Lin, 2001, p. 23). In order for social capital to be obtained, it must occur through a relationship, thus we will consider both aspects of the relationship and the resources gained through the relationship. We have identified four main aspects of social capital that are prevalent in the literature, shown in Table 1.

First, the concept of network size is perhaps the most simple-how many alters (people, or agents of social capital) are influential to a particular students' academic and career decision-making process? While it may only take one person to successfully influence or help facilitate a student's successful entry to the engineering career path, having more people can certainly make it easier to achieve a particular outcome. However, we recognize that knowing how many people students have to access social capital only provides us with a very vague indication of their engineering-related social influences; and, beyond some point, having additional network members may only be able to provide redundant access to resources. In order to gain knowledge of the quality and/or strength of their relationships, we consider 
other measures as well.

Heterophily is a measure of how diverse ego's network is compared to ego's own demographics ("ego" referring to an engineering undergraduate participant in our context). This is an important concept regarding the development of social capital because individuals tend to only have significant contact with alters similar to themselves. Furthermore, ties with alters who are more demographically similar to ego are more likely to be maintained (McPherson et al., 2001) than with alters who are, for example, from a different racial or ethnic background ("cross-racial"), gender ("cross-gender"), or age ("cross-age") than ego. While alters who are more homophilious (demographically alike) to ego may be more willing to go out of their way to provide resources to ego, it is also more likely that the resources provided will be redundant (similar to ego's already available resources). It may be more heterophilious alters who can help ego reach 'new' social capital that can more significantly advance their social position (Lin, 2001; Son \& Lin, 2012); in our context, this would equate to successfully entering an engineering major in college and working towards becoming an engineer.

Table 1. Social Capital Constructs and Operationalization in Name and Resource Generator (NRG) Instrument (adopted from Martin, Miller, \& Simmons, 2014)

\begin{tabular}{|c|c|c|c|}
\hline $\begin{array}{l}\text { Survey } \\
\text { Section }\end{array}$ & \begin{tabular}{|c|}
$\begin{array}{c}\text { Social Capital } \\
\text { Construct }\end{array}$ \\
\end{tabular} & Operationalization & $\begin{array}{l}\text { Sources adopted or adapted } \\
\text { from }\end{array}$ \\
\hline \multirow{7}{*}{$\begin{array}{l}\text { Name } \\
\text { Generator }\end{array}$} & Network Size & $\begin{array}{l}\text { Number of specific people listed } \\
\text { (up to } 8 \text { ) }\end{array}$ & $\begin{array}{l}\text { Lin, 1999, 2001; Burt, 1983; Dika, } \\
\text { 2003; Borgatti, Jones, \& Everett, } \\
\text { 1998; Flap, 1991 }\end{array}$ \\
\hline & \multirow{3}{*}{ Strength of Ties } & Frequency of comm & Burt, 1997; Granovetter, 1973 \\
\hline & & Kin vs. non-kin & Dika, 2003; Lin, 1999b \\
\hline & & Length of relationship & Burt, 1997; Granovetter, 1973 \\
\hline & \multirow{3}{*}{ Heterophily } & $\begin{array}{l}\text { Contacts of a different } \\
\text { race/ethnicity (cross-racial) }\end{array}$ & $\begin{array}{l}\text { Burt, 1983; Dika, 2003; Borgatti et } \\
\text { al., 1998; Son \& Lin, } 2012\end{array}$ \\
\hline & & $\begin{array}{l}\text { Contacts of a different gender } \\
\text { (cross-gender) }\end{array}$ & $\begin{array}{l}\text { Burt, 1983; Borgatti et al., 1998; } \\
\text { Son \& Lin, } 2012\end{array}$ \\
\hline & & 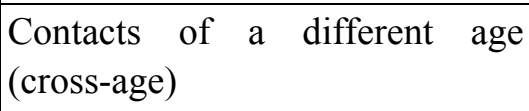 & $\begin{array}{l}\text { Burt, 1983; Borgatti et al., 1998; } \\
\text { Coleman, } 1988\end{array}$ \\
\hline $\begin{array}{l}\text { Resource } \\
\text { Generator }\end{array}$ & $\begin{array}{l}\text { Embedded } \\
\text { Resources }\end{array}$ & $\begin{array}{l}\text { Range, variety, composition of } \\
\text { resources related to engineering } \\
\text { studies and careers }\end{array}$ & $\begin{array}{l}\text { Lin, 1999a, 2008; Van der Gaag \& } \\
\text { Snijders, 2005; Flap, } 1991 \\
\text { (resources modified to reflect those } \\
\text { relevant to engineering pursuits) }\end{array}$ \\
\hline
\end{tabular}

Another dynamic of social relationships is the strength of the tie between alter and ego, that is, how often they communicate, whether or not alter is kin to ego, and how long ego has known alter. Similar to the concept of heterophily, weaker ties, while typically demonstrating lower levels of trust, intimacy, and willingness to go out of their way for ego, are also more likely to be able to "bridge" ego to a collection of new social capital which was previously 
inaccessible (Lin, 2001; Granovetter, 1973; Putnam, 2000). In the context of our study, this could be the difference between a student being able to successfully bridge the gap to engineering and become enrolled in an undergraduate program versus not being able to reach the necessary resources to connect them to engineering and thus not pursing it as a career (even if they had the skills and desire to do so). Research has indicated the latter is more likely to happen to underrepresented students, those from minority ethnic backgrounds (particularly Hispanic and African-American), first generation college students, and those who are from low-income households (Dika, 2012; Martin, Simmons, \& Yu, 2014; Trenor, 2009).

Lastly, we will use measures representing specific engineering-related resources that students reported having available through their social networks (called "embedded resources"). This is really the crux of social capital access, but the previous measures obtained through the Name Generator data are equally important in informing us about how students gain access to the Resource Generator items.

\section{Methodology}

An important first step in understanding what types of social capital engineering undergraduates have available and/or use when making their decision to pursue an engineering degree is to divide students into clusters based on 1) their engineering-related social network characteristics, as measured through the Name Generator (NG) section of the NRG instrument, and 2) their access to resources related to engineering through their social networks as measured through the Resource Generator (RG) section of the NRG.

This study uses data collected from 1,410 undergraduate engineering students recruited by e-mail from five institutions across the United States during a prior phase of our multi-year project (see Martin, Gipson, \& Miller, 2011 and Martin, Miller, \& Simmons, 2014 for full details). A summary of demographics relevant to the goals of the larger study (underrepresented groups) are as follows: females comprised $44 \%$ of our sample; the majority of our participants (56\%) were White or Caucasian, 23\% were Asian or Asian-American, $20 \%$ were Hispanic or Latino/a, 6\% were Black or African-American, and the remaining 4\% of our sample identified with another racial or ethnic background (American Indian or Alaskan Native, Hawaiian or Pacific Islander, or 'other'). The focus on underrepresented students in engineering immediately provides a challenge of access to participants (as representative samples often capture data from few minority populations), so we purposefully over-sampled underrepresented groups in order to contribute richer knowledge of how these students access and utilize social capital resources related to engineering.

First, we present methodological details from two cluster analyses based on NG and RG inputs. Then, we discuss the process and importance of analyzing the clusters to determine which social capital variables yielded significant differences between clusters.

\subsection{Grouping Participants by Social Capital Characteristics Using Two-Step Cluster Analysis}

The first focus of this paper is to present a methodological contribution to the education literature by offering a way to measure and analyze the engineering-related social influences 
students have at their disposal. As we have pointed out, there is not one single way to measure social capital, and measuring social capital can be difficult because it represents an abstract, intangible element of a social relationship. Accordingly, much careful thought must be put into the most appropriate (and usable) way of setting up the cluster analyses, including how many analyses are necessary (given the volume of survey data, including all variables in one analysis would make it difficult to distinguish between clusters thus rendering less useful results than, say, focusing the analysis on one section of the survey at a time), and how the results should be interpreted in a way that is meaningful for higher education practitioners, administrators, policy-makers, and researchers. This is an area where the literature provides some guidance, but this guidance is not consistent between the different areas in which social capital has been used (e.g. sociology, economics, healthcare, and education).

Thus, for the purposes of studying undergraduate students in engineering majors - and we would argue aspects of these findings could be applicable to other college majors as well, particularly in STEM [Science, Technology, Engineering and Mathematics] disciplines-we focus on the four main areas of social capital outlined in the previous section. These include structural characteristics (network size, strength of ties, and heterophily) in addition to details regarding their resource composition (overall resource access, specific resource access, and proportion of their resources accessed via kin, friends, education personnel, or other sources).

Data were analyzed using a two-step cluster analysis. This method was chosen over others (e.g. factor analysis, manual assignment of grouping variables) because of its ability to find patterns in a set of data that have not been pre-selected by the researchers prior to the analysis. That is, rather than using typical/expected groupings of students (e.g. comparing underrepresented groups such as male vs. females, different ethnicities) the cluster analysis technique does not require us to make any presumptions about the data, nor does it begin with any predefined groups. This allows latent patterns in the data (i.e. patterns outside the primary, expected strata) to emerge on their own (Aldenderfer \& Blashfield, 1984). Cluster analysis will thus allow us to determine group-level patterns in the NRG data by identifying similarities in social network indicators and social capital characteristics within each cluster that we either may not have expected to find or did not want to "force" the cluster analysis to produce. Accordingly, we are able to identify differences between clusters for the primary strata (underrepresented groups) by performing statistical analyses on the differences between each cluster with respect to each demographic variable of interest after the clusters were formed around other, non-demographic variables. Other benefits of two-step cluster analysis include being appropriate for large datasets, automatic selection of the optimal number of clusters (optimal based on maximizing distance between clusters), and handling categorical and continuous data simultaneously (IBM, 2013), both of which were present in our data set.

One constraint of using cluster analysis is that as the number of variables included in the analysis increases, the harder it becomes to create separation between the clusters, both by minimizing the distance between each member within a cluster and maximizing the distance between each cluster. Therefore, we strived to capture as many aspects of social capital as possible using as few variables as possible. The input variables, which were designed to measure in aggregate form each participants' network size, strength of ties, heterophily, and 
embedded resources, are listed in more detail in Table 2 (next page).

Table 2. Input Variables for Cluster Analyses

\begin{tabular}{|c|c|c|}
\hline $\begin{array}{c}\text { Cluster } \\
\text { Analysis }\end{array}$ & $\begin{array}{c}\text { Social } \\
\text { Capital } \\
\text { Construct } \\
\end{array}$ & Input Variable \\
\hline \multirow{3}{*}{$\begin{array}{c}\text { Social } \\
\text { Network } \\
\text { Characteristics } \\
\text { (NG) }\end{array}$} & $\begin{array}{c}\text { Network } \\
\text { Size }\end{array}$ & - Number of names listed (1-8) \\
\hline & $\begin{array}{c}\text { Strength of } \\
\text { Ties }\end{array}$ & $\begin{array}{l}\text { - Average frequency of communication with contacts } \\
\bullet \% \text { of names listed who are not kin } \\
\bullet \% \text { of names listed who are "new" contacts } \\
\bullet \% \text { of names listed who are "medium" contacts } \\
\bullet \% \text { of names listed who are "stable" contacts } \\
\bullet \% \text { of names listed who are "lifelong" contacts }\end{array}$ \\
\hline & Heterophily & $\begin{array}{l}\text { - \% of names listed who are cross-racial } \\
\text { - \% of names listed who are cross-gender } \\
\text { - \% of names listed who are cross-age }\end{array}$ \\
\hline $\begin{array}{l}\text { Social Capital } \\
\text { Resources } \\
\text { (RG) }\end{array}$ & $\begin{array}{l}\text { Embedded } \\
\text { Resources }\end{array}$ & $\begin{array}{l}\text { - Overall access to resources } \\
\text { - Resource access provided by kin } \\
\text { - Resource access provided by friends } \\
\text { - Resource access provided by education } \\
\text { - Resource access provided by other } \\
\text { - Yes/No Access to specific resources: } \\
\text { - Earlier-life introductions to engineering (bought you toys } \\
\text { related to science/engineering, helped you with a science fair } \\
\text { project) } \\
\text { - Active forms of help related to engineering (helped you find } \\
\text { an internship in high school, took you to their place of work as } \\
\text { an engineer, paid for your participation in a } \\
\text { science/engineering camp, helped you study for the } \\
\text { SAT/ACT, took you on a college visit) } \\
\text { - Career-related help (worked as an engineer at some point in } \\
\text { their career, told you about their own engineering work, gave } \\
\text { you general information about the work of engineers, talked } \\
\text { to you about career options) } \\
\text { - Academic-related help (gave you college admissions } \\
\text { information, provided you with financial aid information, } \\
\text { helped you research colleges with engineering, gave } \\
\text { information about engineering disciplines) } \\
\text { - Took you to science/engineering museums } \\
\text { - Exposed you to science/engineering experiments } \\
\text { - Recommend courses for you to take to pursue engineering } \\
\text { - Encouraged you to major in engineering }\end{array}$ \\
\hline
\end{tabular}


The input variables were split into two groups, each of which would feed into a separate cluster analysis. Thus, two cluster analyses were performed using the social capital data provided by participants considering the time they were deciding to major in engineering:

1) a cluster analysis based on the social network characteristics of the relationships recorded in the Name Generator, and

2) a cluster analysis based on the availability of engineering-related resources embedded in their social networks, as reported in the Resource Generator.

This approach will allow the cluster analysis procedure to ascertain groupings of students according to the types of social networks they possess based on quantity, strength, and diversity of social relationships as well as by the strength or weakness of their overall access to engineering-related resources, the types of resources they have access to, and the types of people through which they access resources.

\subsection{Statistical Tests for Differences Between Clusters}

Statistical tests were conducted using SPSS version 22 software. Depending on the type of data by which each social capital aspect is measured, either a Kruskal-Wallis $H$ test (three-cluster solutions, interval/ordinal type data), an independent samples t-test (two cluster solutions, interval/ordinal type data) or a Chi-Square test (all clusters, for nominal data, e.g. binary resource comparisons) was performed to determine which social capital variables differed significantly with respect to cluster assignment. For the analyses of the three-cluster Name Generator groupings, a post-hoc pairwise comparison was performed on variables where the K-W or Chi-Square test indicated a significant difference ( $p$-value less than 0.05) to indicate which pairs of clusters differed significantly (one pair, two pairs, or all three being different from each other; significance values with a Bonferroni adjustment were used to ensure a 0.05 level of significance across all hypotheses tested in the post-hoc analysis, thereby reducing the chance of making a Type I error).

\section{Results and Discussion}

The following presents a brief overview of the combined results and discussion section. First, we begin with a summary of the cluster analyses, showing how many clusters were generated and how many participants were assigned to each cluster. Then we present results of tests for statistically significant differences between the clusters in two overall ways. First, we analyzed the social capital input variables used to form each cluster to determine which input variables resulted in a significant difference, and what these differences tell us about the social network composition of each group. Second, we analyzed the differences in demographic characteristics of the members of each cluster which gives us a better understanding of the types of students that are members of each group and which types of students are prone to having particular social capital characteristics. We discuss important observations from each analysis as they relate to engineering education and, in particular, underrepresented groups.

\subsection{Cluster Analysis Results}

First, we will start by presenting a summary of the cluster analysis results. As shown in Table 
3, the Name Generator analysis of social network characteristics yielded a three-cluster solution, dividing participants in to groups of $35 \%, 44 \%$, and $21 \%$ of our sample of 1,410 participants. The Resource Generator analysis of engineering-related resources produced a two-cluster solution, dividing participants into groups of $34 \%$ and $66 \%$ of our sample.

Table 3. Cluster Analysis Results Summary

\begin{tabular}{|l|c|c|c|c|}
\hline \multicolumn{1}{|c|}{ Cluster Analysis } & $\begin{array}{c}\text { Number of } \\
\text { Clusters }\end{array}$ & $\begin{array}{c}\text { Cluster 1 } \\
\text { Size }\end{array}$ & $\begin{array}{c}\text { Cluster 2 } \\
\text { Size }\end{array}$ & $\begin{array}{c}\text { Cluster 3 } \\
\text { Size }\end{array}$ \\
\hline $\begin{array}{l}\text { Social Network Characteristics } \\
\text { (NG inputs) }\end{array}$ & 3 & 486 & 625 & 299 \\
\hline $\begin{array}{l}\text { Social Capital Resource Access } \\
\text { (RG inputs) }\end{array}$ & 2 & 478 & 932 & - \\
\hline
\end{tabular}

\subsection{Differences Between Clusters With Respect to Cluster Analysis Input Variables}

Next, we present results indicating significant differences between the clusters formed by each analysis with respect to each of the input variables that were used to form the clusters. This was done to show which variables were important in distinguishing the clusters from each other and which (if any) noted few differences between each group of participants. A summary of results is provided in Table 4. Following Table 4, we discuss the clusters formed using social network characteristics followed by the clusters formed using data about their access to social capital resources.

Table 4. Summary of Clusters Based on Statistical Differences

\begin{tabular}{|c|c|c|c|c|}
\hline \multirow[b]{2}{*}{$\begin{array}{c}\text { Social Network } \\
\text { Characteristics } \\
\text { (NG inputs) }\end{array}$} & $\begin{array}{l}\text { Cluster } 1(\mathrm{~N}=486) \\
\text { Small, Kin Network }\end{array}$ & \multicolumn{2}{|c|}{$\begin{array}{c}\text { Cluster } 2(\mathrm{~N}=625) \\
\text { Large Network }\end{array}$} & $\begin{array}{c}\text { Cluster } 3(\mathbf{N}=299) \\
\text { Small, Distant Network }\end{array}$ \\
\hline & $\begin{array}{l}\text { Smaller network, strong } \\
\text { ties (more frequent } \\
\text { communication, } 100 \% \\
\text { of their contacts are } \\
\text { lifelong contacts, only } \\
3 \% \text { non-kin, } 7 \% \\
\text { cross-racial) } \\
\end{array}$ & \multicolumn{2}{|c|}{$\begin{array}{c}\text { Larger network, mix of } \\
\text { family and non-kin }(46 \% \\
\text { non-kin, } 52 \% \text { lifelong and } \\
21 \% \text { new contacts, } \\
\text { highest } \% \text { of medium } \\
\text { frequency } \\
\text { communication) }\end{array}$} & $\begin{array}{c}\text { Smaller network, } \\
\text { weaker/more } \\
\text { heterophilious ties } \\
\text { (fewest lifelong, most } \\
\text { non-kin, least frequent } \\
\text { communication) }\end{array}$ \\
\hline \multirow{2}{*}{$\begin{array}{l}\text { Social Capital } \\
\text { Resource } \\
\text { Access } \\
\text { (RG inputs) }\end{array}$} & \multicolumn{2}{|c|}{$\begin{array}{c}\text { Cluster } 1(\mathrm{~N}=478) \\
\text { Less Access to Engineering-Related } \\
\text { Resources }\end{array}$} & \multicolumn{2}{|c|}{$\begin{array}{c}\text { Cluster } 2(\mathrm{~N}=932) \\
\text { More Access to Engineering-Related } \\
\text { Resources }\end{array}$} \\
\hline & \multicolumn{2}{|c|}{$\begin{array}{l}\text { Lower access to resources overall } \\
\text { (slightly), more resources from other } \\
\text { alter types (slightly), significantly } \\
\text { lower access to each individual } \\
\text { resource }\end{array}$} & \multicolumn{2}{|c|}{$\begin{array}{l}\text { Higher access to resources overall } \\
\text { (slightly), more resources from } \\
\text { friends (slightly), significantly higher } \\
\text { access to each specific resource }\end{array}$} \\
\hline
\end{tabular}

\subsubsection{Clusters Based on Name Generator Instrument}

There are many differences between the three clusters formed from the Name Generator 
analysis with respect to the cluster analysis input variables (see Table 5 for data). It is important to note here that since the cluster analysis maximizes the distance between clusters with respect to these very same input variables, we expect to see highly significant differences in this table. However, it is important to know which input variables yielded a significant difference between clusters and which do not, as this gives us information about the specific aspects of social capital that may be most important when considering engineering-related social networks.

Table 5. Differences in Cluster Analysis Input Variables between Clusters Formed on Social Network Characteristics (Name Generator Data)

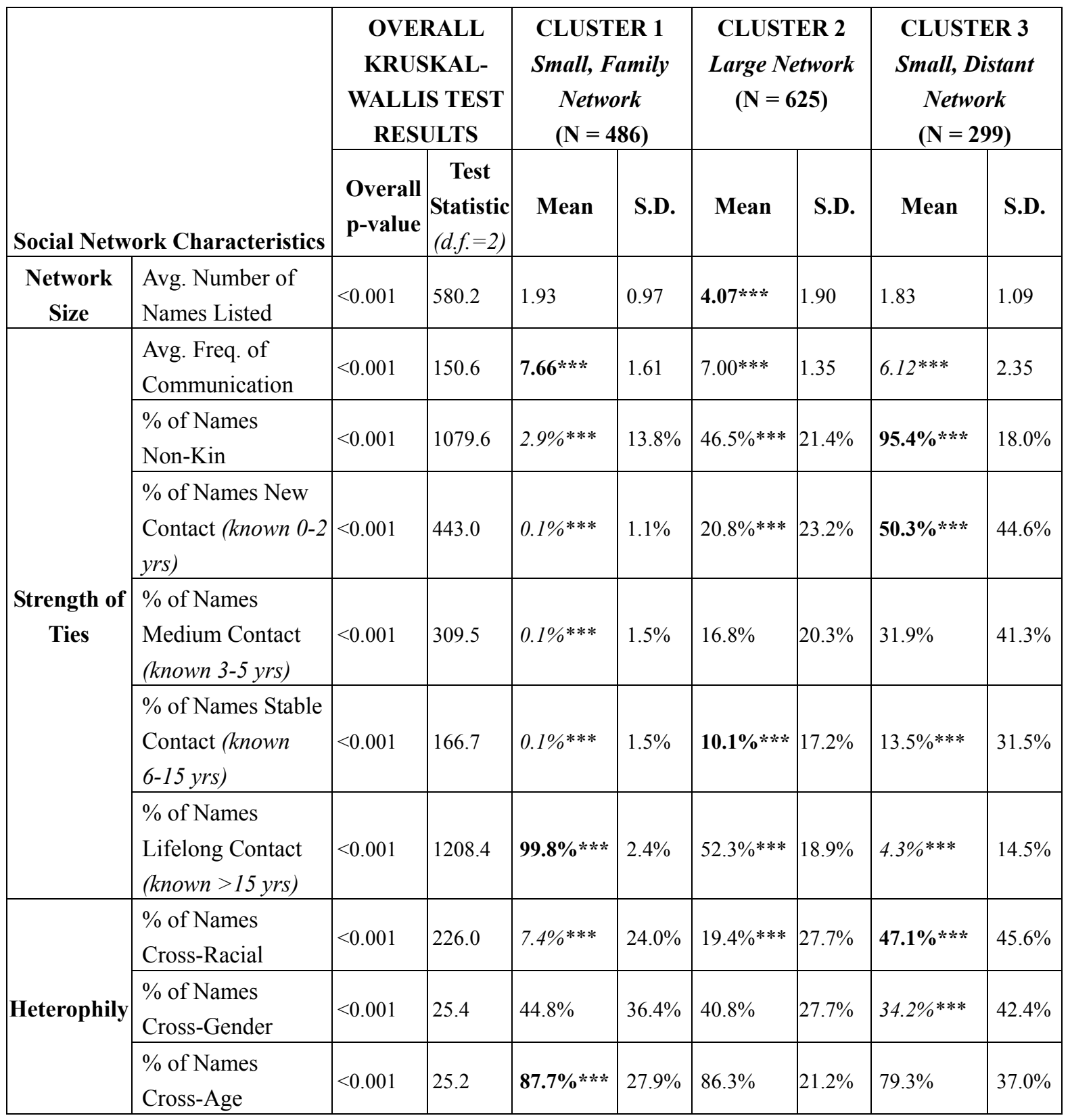

Note: ${ }^{* * *} \mathrm{p}<0.001$, bold indicates statistically highest, italic indicates statistically lowest. 
Three groups of students emerge based on their social network characteristics. One cluster (Cluster 2) reported the largest networks (average of 4.07 names listed) with a mix of kin and non-kin ties with varying strength of relationships. The other two clusters (1 and 3) both reported smaller networks (averages of 1.93 and 1.83 names listed, respectively), but on average the students in Cluster 1 primarily reported kin-centric networks-homophilious networks with people who were of the same ethnic background and family, while Cluster 3's students reported networks which were primarily heterophilious in terms of being composed of primarily non-kin, non-lifelong contacts.

\subsubsection{Clusters Based on Resource Generator Instrument}

The second cluster analysis used input variables specific to the engineering-related resources embedded in each student's social network (see Table 6 for data from statistical tests).

Table 6. Differences in Cluster Analysis Input Variables between Clusters Formed on Social Capital Resource Access (Resource Generator Data)

\begin{tabular}{|c|c|c|c|c|c|c|c|}
\hline & & \multicolumn{2}{|c|}{$\begin{array}{l}\text { TEST RESULTS } \\
\text { Aggregate: } \text { t-test } \\
\text { Binary: } \\
\text { Chi-Square } \\
\end{array}$} & \multicolumn{2}{|c|}{$\begin{array}{l}\text { CLUSTER } 1 \\
\text { Lower } \\
\text { Resources } \\
(\mathbf{N}=478) \\
\end{array}$} & \multicolumn{2}{|c|}{$\begin{array}{c}\text { CLUSTER } 2 \\
\text { Higher } \\
\text { Resources } \\
(\mathbf{N}=932) \\
\end{array}$} \\
\hline \multicolumn{2}{|r|}{$\begin{array}{c}\text { Engineering-related Social Capital Resources } \\
\text { Embedded within Networks }\end{array}$} & p-value & $\begin{array}{c}\text { Test } \\
\text { Statistic } \\
\end{array}$ & $\begin{array}{l}\text { Mean/ } \\
\text { Count }\end{array}$ & S.D. & $\begin{array}{l}\text { Mean/ } \\
\text { Count }\end{array}$ & S.D. \\
\hline \multirow{5}{*}{ 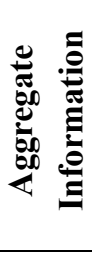 } & $\%$ of Resources Overall (binary yes/no) & $<0.001$ & -35.5 & $52 \%$ & $20 \%$ & $83 \% * * *$ & $37 \%$ \\
\hline & $\%$ of Resources from Friends & $<0.001$ & -4.1 & $14 \%$ & $18 \%$ & $17 \% * * *$ & $14 \%$ \\
\hline & $\%$ of Resources from Other & 0.003 & 3.0 & $6 \% * * *$ & $15 \%$ & $4 \%$ & $7 \%$ \\
\hline & $\%$ of Resources from Education & 0.246 & -1.2 & $30 \%$ & $24 \%$ & $31 \%$ & $30 \%$ \\
\hline & $\%$ of Resources from Kin & 0.915 & -0.1 & $48 \%$ & $30 \%$ & $48 \%$ & $23 \%$ \\
\hline \multirow{8}{*}{ 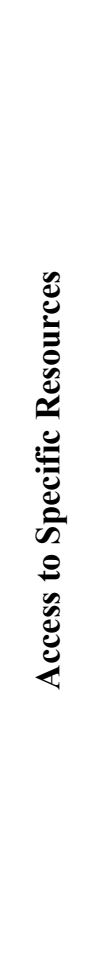 } & Recommend courses for engineering & $<0.001$ & 269.8 & $54 \%$ & - & $100 \% * * *$ & - \\
\hline & $\begin{array}{l}\text { Early-life influences (bought you } \\
\text { science/engineering toys, e.g., chemistry set; } \\
\text { helped with science fair project) }\end{array}$ & $<0.001$ & 376.9 & $64 \%$ & - & $100 \% * * *$ & - \\
\hline & Exposed you to science/engineering experiments & $<0.001$ & 181.0 & $68 \%$ & - & $100 \% * * *$ & - \\
\hline & $\begin{array}{l}\text { Active influences (helped you find an internship, } \\
\text { took you to a place of engineering work, paid for } \\
\text { engineering camp, helped you study for the SAT, } \\
\text { took you on college visits) }\end{array}$ & $<0.001$ & 130.7 & $74 \%$ & - & $100 \% * * *$ & - \\
\hline & $\begin{array}{l}\text { Career related help (worked as an engineer, told } \\
\text { you about their own experiences working in } \\
\text { engineering, gave general information about the } \\
\text { work of engineers, talked about career options) }\end{array}$ & $<0.001$ & 241.8 & $76 \%$ & - & $100 \% * * *$ & \\
\hline & Took you to science/engineering museums & $<0.001$ & 615.7 & $55 \%$ & - & $80 \% * * *$ & - \\
\hline & $\begin{array}{l}\text { Academic related help (gave you college } \\
\text { admissions or financial aid information, helped } \\
\text { you research colleges with engineering, gave } \\
\text { information about engineering majors) }\end{array}$ & $<0.001$ & 334.6 & $87 \%$ & - & $100 \% * * *$ & - \\
\hline & Encouraged you to major in engineering & $<0.001$ & 49.6 & $95 \%$ & - & $100 \% * * *$ & - \\
\hline
\end{tabular}


The first observation that stands out is not all of the aggregate resource variables resulted in a significant difference between clusters. Overall resource access was the best performing input, and along with resources from friends and resources from other sources resulted in significant differences between the clusters, but the latter two were rather low on the cluster analysis input performance measures. The statistical differences, while significant, are subtle. Students had similar access to resources from education personnel and family members, indicating the presence of these resources was not related to their other resource access measures. (As family members and teachers are social ties that every student is almost certainly going to form by the time they reach college, this non-significant finding may simply indicate that these are people to which nearly everyone has access.)

We observe that the first cluster reported significantly lower overall resource access, a theme which was consistent across all of the resource groups, indicating that this group (again, about $34 \%$ of our sample) is comprised of students whose social networks were not embedded with as many engineering-related resources as were the networks of the majority of their peers. This larger cluster of students reported 100\% access to nearly each resource group with only one exception: $80 \%$ of Cluster 2 students knew someone who took them to a museum related to science or engineering.

\subsection{Differences Between Clusters with Respect to Participant Demographics}

Now that we have identified clusters of students based on engineering-related social capital and determined which variables show the most important/interesting differences between clusters, it is important to gain an understanding of who represents each cluster. In other words, are there significant demographic differences between the members of each cluster? Table 7 shows the results of statistical tests answering this question. The over-arching demographic categories of particular interest to our larger research scope (underrepresented groups in engineering) are discussed individually in the following sub-sections.

\subsubsection{Gender}

We observe significant differences between NG clusters with respect to the gender of the cluster members. However, no such differences exist between the RG clusters. So, it appears that male and female engineering students had similar access to various types of engineering-related resources obtained through their social networks, but the social networks providing access to engineering social capital may differ significantly in size and/or type.

\subsubsection{Race/Ethnicity}

Few differences exist between both network- and resource-based clusters with respect to students' racial or ethnic backgrounds. Significantly more Asian students reported smaller networks (evidenced by significantly higher proportions in both small-network clusters and fewer in the large network cluster). White students more frequently reported either small, family-centered networks or large networks (which also contain many kin ties) and significantly less often reported small, distant networks. With respect to resource-based clusters, the lower-resource access cluster contained significantly more Hispanic students, indicating they may be more "at risk" of not having sufficient access to engineering-related social capital than other racial/ethnic groups. 


\subsubsection{Generational Status in College}

First generation college (FGC) students more often reported both smaller, distant networks and networks which provided significantly lower resource access compared to their peers who came from a home with at least one parent having completed a four-year college degree. Thus, FGC students may be another group that is at-risk of not having the necessary social capital that can successfully link them to engineering, a finding further complicated by the fact that FGC students represent an under-studied group in engineering education literature (Trenor, 2009).

Table 7. Test Results for Demographic Differences between Clusters

\begin{tabular}{|c|c|c|c|c|c|c|}
\hline \multicolumn{2}{|c|}{ Demographic Variables } & \multicolumn{3}{|c|}{ NG CLUSTERS } & \multicolumn{2}{|c|}{ RG CLUSTERS } \\
\hline Variables & Variable Level & \begin{tabular}{|c|} 
Cluster 1: \\
Small, Family \\
Networks \\
$(N=486)$ \\
\end{tabular} & $\begin{array}{c}\text { Cluster 2: } \\
\text { Large } \\
\text { Networks } \\
(N=625) \\
\end{array}$ & \begin{tabular}{|c|} 
Cluster 3: \\
Small, Distant \\
Networks \\
$(N=299)$ \\
\end{tabular} & $\begin{array}{l}\text { Cluster 1: } \\
\text { Lower } \\
\text { Resources } \\
(N=478) \\
\end{array}$ & $\begin{array}{l}\text { Cluster 2: } \\
\text { Higher } \\
\text { Resources } \\
(N=932) \\
\end{array}$ \\
\hline \multirow{2}{*}{ Gender } & Female & $46.9 \% * * A$ & $46.2 \% * * A$ & $34.4 \%^{\mathrm{B}}$ & $43.1 \%$ & $44.4 \%$ \\
\hline & Male & $53.1 \%^{\mathrm{B}}$ & $53.8 \%^{\mathrm{B}}$ & $65.6 \% * * A$ & $56.9 \%$ & $55.6 \%$ \\
\hline \multirow{7}{*}{ Race/Ethnicity } & $\begin{array}{l}\text { American Indian or } \\
\text { Alaskan Native }\end{array}$ & $0.4 \%$ & $1.0 \%$ & $2.0 \%$ & $0.4 \%$ & $1.3 \%$ \\
\hline & $\begin{array}{l}\text { Asian or } \\
\text { Asian-American }\end{array}$ & $24.5 \% * * A$ & $18.6 \%^{\mathrm{B}}$ & $28.8 \% * * A$ & $22.0 \%$ & $23.2 \%$ \\
\hline & $\begin{array}{l}\text { Black or } \\
\text { African-American }\end{array}$ & $5.3 \%$ & $7.5 \%$ & $5.7 \%$ & $5.6 \%$ & $6.8 \%$ \\
\hline & Hispanic or Latino & $21.6 \%$ & $18.7 \%$ & $22.1 \%$ & $24.5 \% * * *$ & $18.3 \%$ \\
\hline & $\begin{array}{l}\text { Native Hawaiian or } \\
\text { Pacific Islander }\end{array}$ & $1.6 \%$ & $0.6 \%$ & $2.3 \%$ & $0.8 \%$ & $1.6 \%$ \\
\hline & White or Caucasian & $54.5 \% * * A$ & $59.8 \% * * A$ & $48.5 \%^{\mathrm{B}}$ & $54.0 \%$ & $56.4 \%$ \\
\hline & Other & $1.6 \%$ & $2.2 \%$ & $2.3 \%$ & $2.5 \%$ & $1.8 \%$ \\
\hline $\begin{array}{l}\text { First Generation } \\
\text { College student }\end{array}$ & Yes & $23.9 \%{ }^{\mathbf{B}}$ & $27.7 \%^{\mathrm{B}}$ & $39.8 \% * * * \mathrm{~A}$ & $37.2 \% * * *$ & $24.7 \%$ \\
\hline $\begin{array}{l}\text { Family Income } \\
\text { Level }\end{array}$ & $\begin{array}{l}\text { Average (t-test) } \\
\text { [1-High; 2-Upper } \\
\text { Medium; 3-Medium; } \\
\text { 4-Lower Medium; 5-Low] }\end{array}$ & 2.90 & 2.95 & $3.32 * * *$ & $3.23 * * *$ & 2.90 \\
\hline \multirow{2}{*}{$\begin{array}{l}\text { Transferred from a } \\
\text { different } \\
\text { institution }\end{array}$} & Yes & $15.0 \%$ & $14.4 \%$ & $18.4 \%$ & $19.0 \% * * *$ & $13.6 \%$ \\
\hline & No & $85.0 \%$ & $85.6 \%$ & $81.6 \%$ & $81.0 \%$ & $86.4 \% * * *$ \\
\hline $\begin{array}{l}\text { Knew engineer(s) } \\
\text { before college }\end{array}$ & Yes & $73.9 \% * * * \mathbf{A}$ & $73.6 \% * * * \mathrm{~A}$ & $54.5 \%{ }^{\mathrm{B}}$ & $56.1 \%$ & $76.6 \% * * *$ \\
\hline $\begin{array}{l}\text { Parent has an } \\
\text { engineering } \\
\text { degree }\end{array}$ & Yes & $35.2 \% * * * \mathbf{A}$ & $28.8 \% * * * \mathrm{~A}$ & $9.4 \%^{\mathbf{B}}$ & $19.0 \%$ & $30.9 \% * * *$ \\
\hline
\end{tabular}

Note: Bold indicates significantly higher, ${ }^{* *} \mathrm{p}<0.01, * * * \mathrm{p}<0.001$; ${ }^{\text {superscript }}$ indicates cluster level for Name Generator clusters for pairwise comparison post-hoc analysis: ${ }^{\text {- }}$ higher level, B - lower level; Chi-Square tests were performed for each variable, except Family Income Level where a t-test was used comparing averages on the Likert scale responses. 


\subsubsection{Other Demographic Considerations}

Lastly, there are a handful of other demographic variables that do not represent any one category, but are nonetheless interesting to consider when we discuss the implications for engineering education. We observe that both NG Cluster 3 (small distant network) and RG Cluster 1 (lower resources) contain significantly more students from lower-income families than the high-resource, large network, and small family network groups, indicating income/social status inherited from one's family may impact the volume of engineering influences to which they will have access (and how they will access resources to which they are not connected). Next, we observe that the high-resource cluster contains significantly more students who knew an engineer before college and/or have a parent who has an engineering degree. This observation is not surprising, but it does highlight the potential impact having such a social tie can have for a prospective engineering student.

\section{Conclusions and Implications}

Looking at the Name Generator clusters, we observe that the students with the larger networks containing strong and weak ties were-along with the students with the smaller family-centric networks - more often female, white, knew an engineer before college and/or had a parent with an engineering degree compared to the students with the smaller, more distant networks. While Clusters 1 and 2 were similar to each other with these significant results, there was one difference where Clusters 1 and 3 were actually more similar: more Asian/Asian-American students than the cluster with larger networks.

Looking at the Resource Generator clusters, it is evident that the students with lower resources were more likely to have transferred from a different institution. This cluster also had more Hispanic students and first generation college students. The cluster with higher access to resources was comprised of more students who knew an engineer before college or had a parent with an engineering degree.

A logical question to ask at this point is, "what does this mean for higher education?" As we have noted in prior work, despite decades of research addressing a variety of important questions related to increasing participation in engineering among women, ethnic minorities, first generation college students, and lower-income students, progress has been slow in increasing their representation in engineering higher education and the workforce. By using the approach outlined in this paper, we aim to better understand issues of engineering diversity by taking a novel approach to gaining a better understanding of our target audience. How do students access engineering? How does social capital influence their decisions? Who are the students who report lower levels of social capital, and thus represent a group that may be at risk for insufficient access to engineering opportunities?

In this paper, we make a leap towards answering these questions by revealing initial details about what access to engineering-related social capital looks like and how a certain level of resources forming ego's initial network may be inherited from their families, and is thus based on demographic factors beyond a student's control. This ascribed social capital (Lin, 2001) is different from the social capital resources one is able to attain on their own. A 
student's particular level of ascribed social capital (and how much engineering-specific social capital they are able to attain before college) may impact their ability to successfully enter and persist in engineering higher education. For example, if a unique resource or opportunity had a difference for a FGC student or a Hispanic female, for example, it is likely that a similar social capital resource could have a similar impact on a similar student - but we acknowledge that not all such students will successfully be connected to these opportunities. Thus, if we can find ways to identify what is particularly effective for these groups and specifically target interventions to seek out similar students to provide this opportunity, then this approach could be effective at increasing participation among that group.

All research of this kind is necessarily limited. Our study's exclusive focus on engineering student persisters (that is, all were engineering students at the time they participated in the study) currently prohibits our ability to determine differences in social capital between students who chose engineering as a college major (and subsequently persisted) and those who did not enter engineering as undergraduates and/or switched to an non-engineering major. Our long-term future research plans will focus on this important issue. Immediate future work will focus on performing a similar analysis using second time point data — at the time students were enrolled as an undergraduate in an engineering program. It is important to know what distinguishes students' social capital profiles while they are engineering students and if (and how) this differs from their influences while deciding to major in engineering. Furthermore, this analysis will give us two "snapshots" of our participants' social networks that we can then use to analyze changes in the students' networks over time.

Knowing how and why students gain, increase, or maintain their social capital can be just as important as knowing what types of social capital they accessed in the first place. Furthermore, we expect this knowledge base we are developing (which is specifically targeted to engineering) to be applicable to the wider STEM audience due to similarities in the nature of these programs and the similar sets of skills students in these programs need to be successful. Though the specifics of these findings may be limited to the STEM umbrella, our methodological contribution of the process of quantitatively measuring and analyzing students' social capital characteristics can be customized to collect information about resources relevant to any context, thus making applications of the present study relevant to an even wider academic audience.

\section{Acknowledgement}

This research is sponsored by the National Science Foundation (Grant \#EEC-0950710) to whom we are grateful for making this research possible. Opinions represented here are not necessarily those of the funding agency.

\section{References}

Adler, P. S., \& Kwon, S. (2002). Social capital: Prospects for a new concept. The Academy of Management Review, 27(1), 17-40.

Aldenderfer, M. S., \& Blashfield, R. K. (1984). Cluster Analysis. Thousand Oaks, CA: Sage Publications, Inc. 
Blumberg, B. F., Peiró, J. M., \& Roe, R. A. (2012). Trust and social capital: Challenges for studying their dynamic relationship. In F. Lyon, G. Mollering, \& M. N. K. Saunders (Eds.), Handbook of research methods on trust (pp. 61-71). Northampton, Massachusetts: Edward Elgar Publishing.

Bourdieu, P. (1986). The forms of capital. In J. G. Richardson (Ed.), Handbook of theory and research for the sociology of education (pp. 241-258). Westport, CT: Greenwood Press.

Borgatti, S. P., Jones, C., \& Everett, M. G. (1998). Network measures of social capital. Connections, 21(2), 27-36.

Brown, S. (2005). Student social capital and retention in the college of engineering. Proceedings of the 2005 American Society for Engineering Education Annual Conference \& Exposition.

Brown, S., Flick, L., \& Fiez, T. (2009). An investigation of the presence and development of social capital in an electrical engineering laboratory. Journal of Engineering Education, 98(1), 93-102. http://dx.doi.org/10.1002/j.2168-9830.2009.tb01008.x

Brown, S., \& Hildreth, K. (2007). A comparison of student social networks between students living in and out of living learning communities. Proceedings of the 2007 American Society for Engineering Education Annual Conference \& Exposition,

Burt, R. S. (1983). Range. In R. S. Burt, \& M. J. Minor (Eds.), Applied Network Analysis (pp. 176-194). Beverly Hills, CA: Sage Publications.

Burt, R. S. (1997). A note on social capital and network content. Social Networks, 19(4), 355-373. http://dx.doi.org/10.1016/S0378-8733(97)00003-8

Coleman, J. S. (1988). Social capital in the creation of human capital. American Journal of Sociology, 94 (Supplement: Organizations and Institutions: Sociological and Economic Approaches to the Analysis of Social Structure), S95-S120.

Daily, S. B., Eugene, W., \& Prewitt, A. (2007a). The development of social capital in engineering education to improve student retention. Proceedings of the 2007 ASEE Southeastern Section Annual Conference. Louisville, KY.

Daily, S. B., Eugene, W., \& Prewitt, A. (2007b). Minority retention and success in engineering: Diversifying the pipeline through the development of social capital. Proceedings of the 2007 ASEE Annual Conference. Honolulu, HI.

Dika, S. L. (2003). The effects of self-processes and social capital on the educational outcomes of high school students. Educational Research and Evaluation, $\mathrm{PhD}, 210$.

Dika, S. L. (2012). Relations with faculty as social capital for college students: Evidence from Puerto Rico. Journal of College Student Development, 53(4), 596-610. http://dx.doi.org/10.1353/csd.2012.0051

Flap, H. D. (1991). Social capital in the reproduction of inequality. Comparative Sociology of Family, Health and Education, 20(6), 179-202.

Granovetter, M. (1973). The strength of weak ties. American Journal of Sociology, 78(6), 1360-1380. http://dx.doi.org/10.1086/225469

IBM. (2013). IBM SPSS statistics 22 user's manual. 
Lin, N. (1999a). Building a network theory of social capital. Connections, 22(1), 28-51. http://dx.doi.org/10.1017/CBO9780511815447

Lin, N. (1999b). Social networks and status attainment. Annual Review of Sociology, 25, 467-487. http://dx.doi.org/10.1146/annurev.soc.25.1.467

Lin, N. (2001). Social capital: A theory of social structure in action. Cambridge University Press.

Lin, N. (2008). A network theory of social capital. In D. Castiglione, J. W. Van Deth \& G. Wolleb (Eds.), The Handbook of Social Capital (pp. 50-69). New York: Oxford University Press.

Mannon, S. E., \& Schreuders, P. D. (2007). All in the (engineering) family? - The family occupational background of men and women engineering students. Journal of Women and Minorities in Science and Engineering, 13(4), 333-351. http://dx.doi.org/10.1615/JWomenMinorScienEng.v13.i4.20

Martin, J. P., Gipson, K., \& Miller, M. K. (2011). Developing a survey instrument to characterize social capital resources impacting undergraduates' decisions to enter and persist in engineering. Proceedings of the 41st Annual ASEE/IEEE Frontiers in Education Conference, Rapid City, South Dakota.

Martin, J. P., Miller, M. K., \& Gipson, K. (2011). Utilization of a think-aloud protocol to cognitively validate a survey instrument identifying social capital resources of engineering undergraduates. Proceedings of the 118th ASEE Annual Conference \& Exhibition, Vancouver, BC, Canada.

Martin, J. P., Miller, M. K., \& Simmons, D. R. (2014). Exploring the theoretical social capital "deficit" of first generation college students: Implications for engineering education. International Journal of Engineering Education (Accepted).

Martin, J. P., Simmons, D. R., \& Yu, S. L. (2014). Family roles in engineering undergraduates' academic and career choices: Does parental education attainment mater? International Journal of Engineering Education, 30(1), 136-149.

McPherson, M., Smith-Lovin, L., \& Cook, J. M. (2001). Birds of a feather: Homophily in social networks. Annual Review of Sociology, 27, 415-444. http://dx.doi.org/10.1146/annurev.soc.27.1.415

Nahapiet, J. \& Ghoshal, S. (1998). Social capital, intellectual capital, and the organizational advantage. The Academy of Management Review, 23(2), 242-266.

National Science Foundation. (2012). Women, minorities and persons with disabilities in science and engineering. NSF 11-309. Arlington, VA. Retrieved from http://www.nsf.gov/statistics/wmpd/

Ohland, M., Sheppard, S. D., Lichtenstein, G., Eris, O., Chachra, D., \& Layton, R. A. (2008). Persistence, engagement, and migration in engineering programs. Journal of Engineering Education, 97(3), 259-279. http://dx.doi.org/10.1002/j.2168-9830.2008.tb00978.x

Putnam, R. D. (2000). Bowling alone: The collapse and revival of American community. New York, NY: Simon \& Schuster.

Son, J. \& Lin, N. (2012). Network diversity, contact diversity, and status attainment. Social 
Networks, 34, 601-613. http://dx.doi.org/10.1016/j.socnet.2012.06.006

Tonkaboni, F., Yousefy, A., \& Keshtiaray, N. (2014). The relationship between the curriculum of higher education and social capital. Journal of Education and Training, 1(1), 39-47, http://dx.doi.org/10.5296/jet.v1i1.4599

Trenor, J. M. (2009). A phenomenological inquiry of the major choice process of an overlooked demographic: First generation college students in engineering. Proceedings of the Research in Engineering Education Symposium 2009, Palm Cove, QLD.

Trenor, J. M., Simmons, D. R., \& Archer, E. (2010). The roles of African American Greek organizations in engineering students' educational experiences in a predominantly white institution. Proceedings of the 40th Annual FIE Conference, Washington, D.C.

Van der Gaag, M. P. J., \& Snijders, T. A. B. (2005). The resource generator: Social capital quantification with concrete items. Social Networks, 27(1), 1-29. http://dx.doi.org/10.1016/j.socnet.2004.10.001

\section{Glossary}

NRG: Name and Resource Generator instrument

NG: Name Generator

RG: Resource Generator

STEM: Science, Technology, Engineering, and Mathematics

\section{Copyright Disclaimer}

Copyright reserved by the author(s).

This article is an open-access article distributed under the terms and conditions of the Creative Commons Attribution license (http://creativecommons.org/licenses/by/3.0/). 